\title{
DIFERENCIAS SEMÁNTICAS ENTRE CONSTRUCCIONES CON VERBO DE APOYO Y SUS CORRELATOS VERBALES SIMPLES*
}

\author{
Begoña Sanromán Vilas \\ Universidad de Helsinki \\ begona.sanroman@helsinki.fi
}

\begin{abstract}
Resumen
Frente a la postulada equivalencia entre las construcciones con verbo de apoyo (CVA) o colocaciones verbo-nominales del tipo dar un beso o hacer una promesa -formadas con verbos colocativos desemantizados (ej., dar, hacer o tener)- y sus correlatos verbales simples, por ej., besar o prometer, en este estudio se analizan las diferencias semánticas entre ambas expresiones. Se trata de un paso preliminar para formular reglas de paráfrasis que expliciten las condiciones necesarias para su mutua sustitución. El objetivo del estudio es el de mostrar que la supuesta equivalencia semántica se da sólo a nivel abstracto, cuando nos ocupamos de casos específicos aparecen las diferencias, que clasificaremos en tres grupos: las de tipo general, las que dependen de la clase semántica de unidades léxicas (UULL) y las que se deben a las UULL particulares.
\end{abstract}

PALABRAS CLAVE: construcciones con verbo de apoyo, colocaciones, correlatos verbales simples, colocativos verbales dar, hacer y tener.

\begin{abstract}
Facing the claim that support verb constructions or verb-noun collocations such as dar un beso 'to give a kiss' or hacer una promesa 'to make a promise' -when they contain delexical or light verbs such as dar 'to give', hacer 'to do/make' and tener 'to have'- are semantically equivalent to their correlated single verbs (besar 'to kiss' or prometer 'to promise'), this study focuses on the differences. It represents a preliminary step to formulate paraphrases rules specifying the necessary conditions for their interchangeability. The aim of the study is to prove that the assumed equivalence only takes place in an abstract level while differences emerge in concrete contexts. These differences are classified in three groups: the general ones, those based on the semantic class of the lexical units (LUs) and those depending on particular LUs.
\end{abstract}

KEY WORDS: support verb constructions, collocations, correlated simple verbs, verbal collocates dar 'to give', hacer 'to do/make' and tener 'to have'.

\section{Introducción}

Una práctica bastante común en los diccionarios consiste en utilizar las construcciones con verbo de apoyo (CVA) (Alonso Ramos, 2004) ${ }^{1}$ como dar consejo o tener envidia en sustitución de la definición de una unidad léxica (UL) verbal que funciona como su contrapartida (ej., aconsejar o envidiar); es decir, como si el hecho de tratarse de expresiones pluriverbales capacitase a este tipo de colocaciones verbo-nominales para representar la descom-

\footnotetext{
* Quisiera expresar mi gratitud a la profesora Margarita Alonso Ramos por la lectura de este manuscrito, así como por sus valiosos comentarios y sugerencias bibliográficas. Este trabajo está subvencionado por el Ministerio de Educación y Ciencia a través del proyecto de investigación FFI2008-06479-C02-01/FILO.

1 Wotjak (1998) las llama construcciones verbo-nominales funcionales.
} 
posición semántica de la UL. Decir que ‘dar consejo', 'tener/sentir envidia', 'hacer caricias' o 'decir piropos' son buenas definiciones para aconsejar, envidiar, acariciar y piropear, como se propone en el Diccionario de la lengua española (DRAE), en el Diccionario Salamanca de la lengua española (DSLE) o en el Diccionario del español actual (DEA) es una cuestión que presenta muchas objeciones, pero es también una muestra indudable de la proximidad semántica entre las CVA y sus correlatos verbales ${ }^{2}$.

Es cierto que las CVA, en tanto que relaciones léxicas sintagmáticas, y los verbos simples correspondientes, en su calidad de relaciones léxicas a nivel paradigmático, son fenómenos de la misma naturaleza lógica y como tales, están capacitados para expresar el mismo significado proposicional. Así, cuando un hablante quiere expresar el sentido 'cesar la actividad' puede seleccionar, por ejemplo, una UL en relación sintagmática con reposo como hacer o bien una UL con la que reposo mantiene una relación paradigmática como reposar. En el primer caso, diremos que el colocativo hacer es un verbo de apoyo ${ }^{3}$ (Alonso Ramos, 2004: 18) porque su función es la servir de mero soporte sintáctico al nombre predicativo para la configuración oracional sin añadir (o añadiendo escamente) contenido semántico ${ }^{4}$. En el segundo caso, reposar es un derivado semántico (Polguère y Mel'čuk, 2006), concretamente, la verbalización del nombre predicativo. Y, en efecto, aunque en ocasiones, ambas formas, hacer reposo y reposar, son intercambiables, El médico le recomendó hacer reposo ${ }^{5}$ y El médico le recomendó reposar ${ }^{6}$, no lo son, sin embargo, en todos los contextos. Podemos decir Weimar, la ciudad donde reposan las cenizas de Goethe... ${ }^{7}$ pero no Weimar, la ciudad donde *hacen reposo las cenizas de Goethe... ${ }^{8}$

A la vista de estas y otras particularidades, nuestro objetivo aquí será el de elaborar una primera aproximación encaminada a establecer las diferencias semánticas entre CVA y sus correlatos verbales simples como paso preliminar para poder formular, en el futuro, reglas de paráfrasis que expliciten las condiciones necesarias para su mutua sustitución. En particular, hemos seleccionado un grupo de nombres predicativos -golpe, promesa, sospecha, etc.- que admiten la combinación sintagmática con los verbos de apoyo dar, hacer y tener formando CVA como dar un golpe, hacer una promesa, tener una sospecha y que tienen derivados semánticos verbales ${ }^{9}$ como golpear, prometer o sospechar. Como verbos colocativos hemos

2 En el Diccionario para la enseñanza de la lengua española (DELE), aconsejar y envidiar también se definen como 'dar consejo' y 'sentir o tener envidia', respectivamente. Sin embargo, para describir acariciar se opta por 'mostrar afecto rozando suavemente con la mano' y para piropear se recurre a 'dirigir expresiones de admiración a una persona'.

3 Aparte de verbos de apoyo (Dubský, 1990b, 1998; Piera y Valera, 1999; Alonso Ramos, 2004) estos verbos han sido denominados verbes support dentro de la teoría del léxico-gramática (por ejemplo, Gross, 1981), light verbs en algunas propuestas de la gramática generativa, verbos vicarios (Mendívil Giró, 1999) o verbos funcionales (Koike, 2001), entre otros.

4 Para Tornel Sala (2000:25), que denomina a estas construcciones perifrasis verbo-nominales, «el verbo se comporta como un verdadero auxiliar (gramaticalizándose) y sirviendo como simple vector de actualización verbal de los segmentos nominales a los que acompaña».

5 Ejemplo extraído de Internet: <http://www.yoargentino.us/2008/08/> [04/08/2009].

6 Internet: <http://www.tvyespectaculos.com/2007/11/05/kylie-minogue-cancela-su-gira-mundial-2008-por-problemas-de-salud $>$ [04/08/2009].

7 Ejemplo extraído del Corpus de referencia del español actual (en adelante, CREA).

8 Véase un ejemplo semejante con hacer reposo en Piera y Valera (1999: 4416).

9 La noción de derivación semántica será tratada con más detalle en el apartado 2. 
seleccionado únicamente dar, hacer y tener por dos motivos principales: en primer lugar, son los más utilizados en español en esta función de verbos de apoyo; en segundo lugar, son los más neutros, ya que en principio, carecen de matices aspectuales -como por ejemplo coger, cobrar o tomar cariño, que focalizan la fase en la que se empieza a sentir el cariño-, causativos -como meter miedo, sembrar el pánico o suscitar los celos, que indican la presencia de un participante que causa la emoción- o diafásicos - dar un grito pertenece a un registro neutro frente a pegar un grito, que es informal y emitir un grito, formal-.

La relación de paráfrasis entre este tipo de colocaciones y sus contrapartidas verbales simples no ha sido muy estudiada. La mayoría de los trabajos clasifica los diferentes tipos de colocaciones verbo-nominales en función del grado de desemantización del colocativo y de su equivalencia a un verbo pleno ${ }^{10}$, pero no hemos encontrado estudios que analicen en profundidad las diferencias entre las colocaciones en las que el verbo colocativo ha alcanzado el grado máximo de vaciedad semántica -como en los casos señalados de dar, hacer y tener-y sus correlatos verbales independientes ${ }^{11}$.

Nuestro objetivo concreto será el de mostrar que la supuesta equivalencia semántica entre las mencionadas colocaciones y sus correlatos verbales simples se da sólo a nivel abstracto o teórico, a medida que nos ocupamos de casos específicos aparecen las diferencias. Prevemos además que estas diferencias pueden ser clasificadas en tres grupos: las que afectan regularmente a uno u otro tipo de expresión, las que dependen de la clase semántica de las UULL y las que se deben a cada una de las UULL en particular. De acuerdo con la clasificación, las diferencias del primer tipo habrán de consignarse en una gramática puesto que se dan de manera general y sistemática; sin embargo, las del segundo y tercer tipo tendrán que ser registradas en el diccionario, ya que son de naturaleza bien léxica bien léxico-semántica.

Los datos de esta investigación se han obtenido principalmente a partir del Corpus de referencia del español actual (CREA) y de diversos diccionarios de español (véase la bibliografía). Se han extraído también ejemplos de diversas páginas de Internet. Como marco teórico y metodológico se sigue la Lexicología explicativa y combinatoria (LEC) (Mel'čuk et alii, 1995), puesta en práctica en diccionarios como el Dictionnaire explicatif et combinatoire du français contemporain (DEC) (Mel'čuk et alii, 1984-1999), el Diccionario de colocaciones del español (DiCE) (Alonso Ramos, 2003, 2005), el Lexique actif du français (LAF) (Mel'čuk y Polguère, 2007) o el Dictionnaire fondamental de l'information et de l'Internet (DiCoInfo) (L'Homme, 2008). La LEC constituye un componente esencial de la teoría lingüística conocida como Teoría sentido-texto (TST) (Mel'čuk y Žolkovskij, 1970; Mel'čuk, 1997).

El presente estudio se organiza del siguiente modo. Tras esta introducción, trataremos las nociones de colocación, en general, y de CVA, en particular, así como la de derivado semántico, haciendo referencia a la herramienta que se utiliza en la LEC para su descripción (apartado dos). A continuación, nos centraremos en las CVA y los verbos plenos equivalentes,

10 Véanse los trabajos de Wotjak (1998), Koike (2001), Miguel (2006), entre otros.

11 Algunos autores han señalado explícitamente que estas colocaciones no añaden ningún valor semántico respecto al significado de los verbos simples (Koike, 2001: 83; Blasco Mateo, 2002: 54; entre otros.). En cambio, Alonso Ramos (2004: 133) ha manifestado que la relación entre estas colocaciones y los verbos plenos «no puede ser establecida mecánicamente, sino que debe ser sometida a un estudio semántico particular». En esta línea, contamos con observaciones aisladas acerca de algunas diferencias entre ambas expresiones a nivel informativo y de registro (Martín Mingorance, 1998: 22-23) o de carácter aspectual (Miguel, 2006: 1293). 
explicando los criterios de selección que se han seguido con vistas a garantizar, como punto de partida, el máximo grado de equivalencia entre ambas expresiones (apartado tres). En el apartado siguiente expondremos en detalle los resultados del análisis, especificando qué diferencias semánticas encontramos entre ambas construcciones (apartado cuatro). Por último (apartado cinco), presentaremos unas consideraciones finales a modo de conclusión.

\section{Las nociones de colocación y derivado semántico en la Lexicología explicativa y combinatoria}

El concepto de colocación ${ }^{12}$ que adoptamos en este estudio es el descrito por Hausmann (1979) y Mel'čuk (1995). En este sentido, una colocación es una combinación de dos UULL, la base, escogida libremente por el hablante de acuerdo con sus necesidades comunicativas, y el colocativo, seleccionado de manera léxicamente restringida en función de la base para expresar un sentido particular. Así, por ejemplo en las colocaciones éxito CLAMOROSO ${ }^{13}$, fiebre ALTA y promesa SOLEMNE, las bases nominales éxito, fiebre y promesa seleccionan los colocativos adjetivales CLAMOROSO, ALTO y SOLEMNE para expresar el sentido 'intenso'. Es de notar que la selección léxica es restringida, pues si intercambiamos los adjetivos, las combinaciones resultantes no son aceptables: *éxito ALTO, *fiebre SOLEMNE y *promesa CLAMOROSA. Si en lugar de bases nominales, tenemos bases adjetivales como contento o verbales como dormir, el sentido 'intenso' se expresará por medio de los colocativos LA MAR DE (contento) y (dormir) COMO UN TRONCO.

Dentro de la LEC, las colocaciones se describen por medio de las llamadas funciones léxicas (FFLL) (Wanner, 1996; Mel'čuk, 1998). Las FFLL son sentidos generales, normalmente abstractos - del tipo 'intenso' como el que acabamos de describir- que se producen al asociar dos elementos: un argumento, la base de la colocación y un valor, el conjunto de UULL de la lengua que se combinan con la base de manera restringida. Así, al igual que la función matemática 'raíz cuadrada' aplicada sobre el argumento 25 tiene como valor 5, la FL Magn -con el sentido 'intenso'- aplicada al argumento éxito presenta como valores CLAMOROSO, FULMINANTE, ROTUNDO, que representamos del siguiente modo: Magn $(e ́ x i t o)=$ CLAMOROSO, FULMINANTE, ROTUNDO.

Además de expresar un sentido abstracto como 'intenso' en el caso de Magn u otros como 'una porción (unidad) de' en la FL S ing -DIENTE DE AJO, RAYO DE SOL-o 'tal como debe ser' en la FL Ver -promesas CUMPLIDAS, plata DE LEY-, las FFLL también pueden servir para indicar un papel sintáctico particular. Así, la FL Oper, aplicada a nombres, da como valores verbos (cuasi-)vacíos de contenido semántico que toman el nombre como OD y uno de los actantes del nombre como sujeto gramatical. Si se trata de Oper ${ }_{1}$, aplicada a respeto (respeto de $X$ por Y), los verbos resultantes, SENTIR, TENER, DEBER, TRIBUTAR, etc., tienen como sujeto el primer actante del nombre (X), por ejemplo, Los alumnos SIENTEN respeto por el profesor; en cambio, si se trata de Oper ${ }_{2}$, el sujeto de los valores verbales, GOZAR, TENER, es el segundo actante del nombre (Y): El profesor GOZA del respeto de los alumnos. Obsérvese que TENER puede funcionar tanto como valor de la FL Oper ${ }_{1}$ de respeto, por ejemplo, en Los alumnos le TIENEN respeto al profesor como de Oper ${ }_{2}$, El profesor TIENE el respeto de los alumnos.

12 Para un análisis más detallado del concepto de colocación, véanse Alonso Ramos (1994-1995) y Bosque (2001), entre otros.

13 En este apartado marcamos los colocativos en letras versales, además de la cursiva típica de los ejemplos. 
Las CVA objeto de este estudio en tanto que colocaciones verbo-nominales, formadas por un verbo parcial o totalmente desemantizado y un nombre predicativo que funciona como

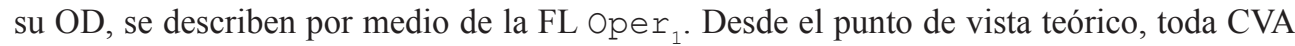
equivale a la verbalización del nombre predicativo que funciona como OD en la CVA -TENER respeto $\Rightarrow$ respetar, DAR un paseo $\Rightarrow$ pasear, etc.-- Dentro de la LEC, a esta verbalización -en relación léxica paradigmática con el nombre predicativo- se le da el nombre de derivado semántico. En un sentido amplio, por derivación semántica se entiende la relación entre dos UULL, $\mathrm{L}_{1} \mathrm{y} \mathrm{L}_{2}$, en la que $\mathrm{L}_{1} \mathrm{y} \mathrm{L}_{2}$ mantienen una relación semántica recurrente en la lengua que se manifiesta generalmente de forma morfológica (Polguère y Mel'čuk, 2006: 68). Así, a partir de asombro podemos formar derivados semánticos como asombrarse, asombrado, asombroso, asombradizo, etc. Los derivados semánticos, al igual que las colocaciones, se describen por medio de las FFLL. Así, mientras asombrarse representa un valor de la FL V 'verbalización', asombrado, asombroso y asombradizo son valores de las FFLL A 'adjetivo para nombrar al experimentador del asombro', $A_{2}$ 'adjetivo para nombrar la causa del asombro' y Able ' adjetivo para nombrar al que es propenso a sentir asombro', respectivamente ${ }^{14}$.

\section{Construcciones con verbo de apoyo y sus correlatos verbales simples}

En la Tabla 1 presentamos las CVA - dar un beso, hacer una promesa, tener una sospecha, etc.- con los correlatos verbales libres - besar, prometer, sospechar, etc.- que han sido utilizados como corpus de este estudio. Como describimos en el apartado anterior, se trata de colocaciones formadas por dos componentes - los colocativos verbales dar, hacer y tener como valores de la FL Oper y las bases de la colocación (beso, prome$s a$, sospecha, etc.)- en relación con los derivados semánticos verbales de las bases de las colocaciones o valores de la $\mathrm{FL} V_{0}$. En lo que sigue se explicarán las características semántico-aspectuales y gramaticales generales de los colocativos, nombres predicativos y verbos derivados, así como los criterios utilizados para seleccionar el grupo particular de CVA y sus derivados.

\begin{tabular}{|c|c|c|}
\hline \multicolumn{2}{|r|}{ COLOCACIONES } & \multirow{2}{*}{ DERIVADOS SEMÁNTICOS VERBALES } \\
\hline COLOCATIVOS & BASES & \\
\hline$D A R$ & beso, golpe, orden, paseo, permiso & $\begin{array}{l}\text { besar, golpear, ordenar, pasear, } \\
\text { permitir }\end{array}$ \\
\hline HACER & $\begin{array}{c}\text { broma, limpieza, promesa, uso, } \\
\text { viaje }\end{array}$ & bromear, limpiar, prometer, usar, viajar \\
\hline TENER & respeto, sospecha, sueño, susto, tos & $\begin{array}{c}\text { respetar, sospechar, soñar, asustarse, } \\
\text { toser }\end{array}$ \\
\hline
\end{tabular}

Tabla 1. Selección de CVA y derivados semánticos verbales usados en el estudio

14 Dentro de la LEC, los DEC cuentan con una zona especial en la entrada lexicográfica dedicada a la coocurrencia léxica restringida del lema. En ella se describen todas las colocaciones y derivados semánticos de la UL usando la herramienta de las FFLL. En el $L A F$ y en el DiCE, además de las FFLL, cuya interpretación puede resultar difícil al usuario, se añade una glosa que explica el sentido de la misma (Alonso Ramos, 2006). 


\subsection{Clasificación semántico-aspectual de los nombres de las construcciones con verbo de apoyo}

Las bases de las colocaciones, que constituyen un total de quince nombres predicativos -beso, broma, golpe, limpieza, orden, paseo, permiso, promesa, respeto, sospecha, sueño, susto, tos, uso y viaje-, pueden clasificarse desde un punto de vista semántico-aspectual en acciones, actos, actividades, actitudes, estados, procesos y acontecimientos, siguiendo dos criterios: la volición y la duración (véase la Tabla 2). Distinguimos los hechos volitivos de los no volitivos en que los primeros están bajo el control de un agente. Así ocurre con las acciones y los actos frente a los acontecimientos. A su vez, los hechos durativos como las acciones y los procesos se oponen a los puntuales, por ejemplo, actos y acontecimientos ${ }^{15}$.

\begin{tabular}{|c|c|c|c|c|c|c|}
\hline & ACCIÓN & ACTO & ACTIVIDAD & ACTITUD & ESTADO & ACONTECIMIENTO \\
\hline DAR & paseo & $\begin{array}{c}\text { beso, golpe, } \\
\text { orden, permiso }\end{array}$ & - & - & - & - \\
\hline HACER & $\begin{array}{c}\text { viaje, } \\
\text { uso }\end{array}$ & broma, promesa & limpieza & - & - & - \\
\hline TENER & - & - & - & respeto & $\begin{array}{c}\text { tos, sueño, } \\
\text { sospecha }\end{array}$ & susto \\
\hline
\end{tabular}

Tabla 2. Clasificación semántico-aspectual de los nombres de las CVA

De acuerdo con los criterios señalados, las acciones nombran 'lo que una persona hace voluntariamente durante cierto tiempo'. En nuestros datos, son acciones paseo, viaje y uso porque los tres requieren un agente y extensión en el tiempo. Obsérvese en (1) cómo viaje lleva el verbo en primera persona y se combina con el modificador temporal encabezado por durante $^{16}$.

(1) [...] hice un viaje a Sevilla durante los más tórridos días de 1938... (CREA)

Los actos o 'acciones momentáneas' representan la categoría mayoritaria. Incluimos en ella beso, golpe, broma, orden, permiso y promesa. Al igual que las acciones, siguen requiriendo un agente, pero a diferencia de ellas, carecen de extensión en el tiempo, hecho que se puede apreciar a través de diferentes tests (véanse los ejemplos en (2) y (3)):

(2) a. Sandra sonrió, se levantó y le dio un beso en la frente. (CREA) b. *Sandra sonrió, se levántó y dejó de darle un beso en la frente.

(3) a. Julio hizo una promesa vaga, referida al domingo... (CREA)

b. *Julio pasó tres segundos haciendo una promesa...

c. *Julio lleva tres segundos haciendo una promesa...

15 Para esta clasificación nos hemos inspirado en Lyons (1980), Mighetto (1992) y Alonso Ramos (2004). Nuestra intención ha sido la de buscar nombres para las categorías que se correspondan con su descomposición semántica y no etiquetas semánticas universales, independientes de la lengua en cuestión. En consecuencia, esta clasificación es específica para el español.

16 Los complementos introducidos por durante suelen utilizarse como test para probar que un determinado predicado es durativo y no puntual. Véase Miguel (1999: 3033), entre otros. 
La imposibilidad de combinarse con los verbos dejar de (o cesar de) suele utilizarse como prueba para detectar hechos puntuales (Alonso Ramos, 2004: 168, 185). En (2b), comprobamos que beso no admite el verbo dejar de ${ }^{17}$. De acuerdo con Miguel (1999: 3035), las expresiones del tipo X pasó Y tiempo $V$-ndo o X lleva Y tiempo V-ndo tampoco son admitidas por los predicados que carecen de extensión en el tiempo. En (3b) y (3c) constatamos que promesa rechaza ambas expresiones.

Las actividades, como por ejemplo limpieza, comparten con las acciones su carácter volitivo y su extensión en el tiempo; para diferenciarlas de ellas, definimos una actividad como 'el conjunto de acciones realizadas por una persona en un orden determinado y con un objetivo específico'. Entre los nombres seleccionados encontramos también una actitud, respeto. Las actitudes hacen referencia a 'la tendencia de una persona a actuar de una forma determinada con respecto a un objeto, motivada por un pensamiento positivo o negativo hacia el mismo'. A diferencia de los estados y las cualidades, con los que guardan ciertas semejanzas, las actitudes admiten la forma imperativa. Adviértase el contraste entre el uso del imperativo con una actitud (Ten respeto) frente a su uso con un estado (*Ten cansancio) o una cualidad (*Ten belleza).

Usamos acontecimiento para nombrar 'hechos puntuales no volitivos' y proceso para 'hechos durativos no volitivos'. Por su carácter no volitivo y momentáneo, hemos clasificado susto como un acontecimiento. En el caso de sueño - 'imágenes que se suceden durante el sueño' ${ }^{18}$ - y de tos, hemos dudado entre considerarlos procesos o estados, categorías que mantienen entre sí diferencias muy sutiles (véase Alonso Ramos, 2004: 189). Finalmente, teniendo en cuenta las observaciones de Lyons (1980: 644) acerca de que los estados son homogéneos y no cambian a lo largo de sus fases sucesivas, mientras que los procesos no lo son, los hemos tratado como estados. También dentro de la categoría de los estados, incluimos sospecha, si bien su naturaleza cognitiva lo aleja de los anteriores.

\subsection{Comportamiento gramatical de las construcciones con verbo de apoyo y sus co- rrelatos verbales}

En su relación con la presencia o ausencia del artículo y la posibilidad de construirse en singular o plural, las colocaciones resultantes se comportan del siguiente modo (véase la Tabla 3): 1) la mayoría de ellas pueden construirse en singular y en plural y llevan artículo obligatorio en singular, por ejemplo, dar un beso/dar besos o hacer una broma/hacer bromas; 2) algunas de estas colocaciones se construyen sólo en singular y sin artículo, por ejemplo, dar permiso ${ }^{19}$ o hacer uso; 3) otras llevan artículo facultativo y admiten número singular y plural como dar (una/la) orden/dar órdenes; y 4) el artículo es facultativo y sólo pueden ir en singular, por ejemplo, hacer (la) limpieza.

17 Si se le da una lectura habitual, el ejemplo sería gramatical (véase Alonso Ramos, 2004: 185).

18 Describimos SUEÑO como un vocablo polisémico que consta de las siguientes acepciones: sueño1 = 'estado de dormir de X' (Pedro necesita ocho horas de sueño); sueño2 = 'ganas de dormir de X' (Pedro se acostó porque tenía sueño); sueño3 = 'imagen que aparece durante el sueño1' (En mi sueño veía un bosque repleto de árboles que sonreían); sueño4 = 'ideal de X’ (El gran sueño de Pedro es ser bombero). (Sanromán Vilas, 2003: 51).

19 Nótese que dar un permiso, con artículo, se refiere a una autorización escrita. 


\begin{tabular}{|c|c|c|}
\hline & SINGULAR Y PLURAL & SINGULAR \\
\hline $\begin{array}{l}\text { ARTíCULO } \\
\text { OBLIGATORIO }\end{array}$ & $\begin{array}{c}\text { dar un beso/dar besos; } \\
\text { dar un golpe/dar golpes; } \\
\text { dar un paseo/dar paseos; } \\
\text { hacer una broma/hacer bromas; } \\
\text { hacer una promesa/hacer promesas; } \\
\text { hacer un viaje/hacer viajes; } \\
\text { tener una sospechas/tener sospechas; } \\
\text { tener un sueño/tener sueños; } \\
\text { tener un susto/tener sustos; }\end{array}$ & . \\
\hline ARTÍCULO CERO & - & $\begin{array}{l}\text { dar permiso; } \\
\text { hacer uso; } \\
\text { tener respeto; }\end{array}$ \\
\hline $\begin{array}{l}\text { ARTíCULO } \\
\text { FACULTATIVO }\end{array}$ & dar (una/la) orden/dar órdenes; & $\begin{array}{l}\text { hacer (la) limpieza; } \\
\text { tener (la) tos; }\end{array}$ \\
\hline
\end{tabular}

Tabla 3. Comportamiento de las colocaciones analizadas en relación con la presencia o ausencia de artículo y la variación de número gramatical

Dado que el objetivo del estudio es mostrar las diferencias entre los pares colocación verbo-nominal y verbo correspondiente, hemos utilizado una serie de criterios de selección para garantizar, en principio, el máximo grado de equivalencia entre ambas expresiones. En lo que respecta a las UULL predicativas -el nombre, base de la colocación, y el verbo pleno-, hemos tenido en cuenta que entre ellas exista siempre un vínculo morfológico y un vínculo semántico. Desde el punto de vista de la derivación morfológica, pueden darse las siguientes posibilidades: 1) los verbos plenos provienen de los nombres correspondientes, por ejemplo, bromear de broma (brom $(a)+e+-a r)$, o a la inversa, 2) los nombres provienen de los verbos como respeto de respetar (respet(ar) $+-o$ ); 3 ) verbo y nombre derivan del mismo adjetivo, por ejemplo, limpiar y limpieza de limpio (limpi $(o)+$-ar y limpi $(o)+-e z a)$; y 4) los verbos son derivados parasintéticos denominales como asustar, formado con prefijación y sufijación a partir de susto $(a-+\operatorname{sust}(o)+-a r)$. De acuerdo con el criterio morfológico, quedan fuera de los límites de este estudio pares como dar clase y enseñar, hacer fuego y disparar o echar un sueño y dormir. Desde el punto de vista semántico, hemos tenido en cuenta que entre el nombre y el verbo exista un vínculo de significado evidente. Así, la relación semántica entre golpear 'dar uno o varios golpes repetidos' y golpe está garantizada porque en la definición de golpear se incluye golpe. Sin embargo, la relación semántica entre los verbos colar 'pasar por un lugar estrecho' o colarse 'introducirse a escondidas o sin permiso' y cola 'hilera de persona que esperan vez' la consideramos demasiado remota para tenerla en cuenta en este estudio.

\subsection{Los verbos de apoyo dar, hacer y tener}

En lo que se refiere a la selección de las UULL funcionales -es decir, los colocativos dar, hacer y tener ${ }^{20}$, hemos seguido los siguientes criterios: la frecuencia, la vaciedad de

20 Para un estudio detallado del colocativo dar, puede consultarse Alonso Ramos (1997). El REDES ofrece una rigurosa descripción de las bases nominales con las que se combina este colocativo -alrededor de una decena de 
contenido semántico, la neutralidad diafásica y la imposibilidad de intercambio mutuo. De acuerdo con el criterio de la frecuencia, Koike (2001: 84-87) indica que el verbo más usado para formar colocaciones verbo-nominales es dar, en segundo lugar se situaría tener y en tercero, hacer $^{21}$. Además de su uso particular como colocativos, se trata de verbos muy productivos en general, pues en el diccionario de Davies (A Frequency Dictionary of Spanish. Core Vocabulary for Learners, FDS, 2006), donde se listan las cinco mil palabras más frecuentes en español, tener ocupa el puesto 18, hacer el 25 y dar, el 39.

El segundo criterio que hemos considerado en la selección de los colocativos es el de su vaciedad semántica. Si bien es cierto que se dice que todos los colocativos pierden su sentido básico como UULL plenas para funcionar como meros soportes sintácticos de la estructura en la que se insertan, esto no ocurre en igual grado con todas las UULL. Algunos verbos colocativos conservan una parte de su significado original que los habilita como verbos fasales, causativos o realizativos. En el caso de los fasales, coger respeto, guardar respeto o perder el respeto, éstos aportan los sentidos aspectuales de fase 'empezar a (sentir respeto)', 'continuar (sintiendo respeto)' y 'dejar de (sentir respeto)', respectivamente. Los causativos añaden el sentido 'causar/hacer que' como dar envidia, 'hacer que alguien sienta envidia' o sofocar una rebelión 'hacer que la rebelión no tenga lugar'. Los realizativos, a su vez, son aquellos que realizan el objetivo inherente al nombre, por ejemplo, cumplir una promesa o saldar una deuda. Dar, hacer y tener, en combinación con los nombres seleccionados no aportan ninguno de los sentidos mencionados.

Desde el punto de vista estilístico, dar, hacer y tener son también colocativos neutros. Así por ejemplo, dentro de un continuo de formalidad-coloquialidad, dar en dar un golpe es neutro frente a variantes como asestar o administrar (un golpe), por un lado, o pegar, mandar o soltar (un golpe) por otro, por pertenecer las primeras a un registro más formal y las segundas a uno más coloquial.

El carácter neutro de dar, hacer y tener que, sin duda, es una de las razones de su frecuencia en el habla, es explotado también en la enseñanza de la lengua española para ampliar el vocabulario de los aprendices. En este sentido, son clásicos los ejercicios en los que el aprendiz debe reemplazar alguno de estos verbos por otro «más apropiado». En el ejemplo siguiente (4) ofrecemos una muestra en la que se pide al estudiante que sustituya tener por otro verbo ${ }^{22}$ :

(4) a. Tengo dolor en el estómago. (sentir)

b. Los cantantes tuvieron bastante éxito. (obtener)

c. En la clase, tengo el cuarto puesto. (ocupar)

d. Tiene una enfermedad muy grave. (padecer)

e. Me gustaría tener una aventura emocionante. (correr)

Tras estas consideraciones, podemos añadir que dar, hacer y tener entran dentro de la categoría de verbos de apoyo «puros», es decir, verbos que se han vaciado de su contenido

páginas-; sin embargo, no hemos encontrado información comparable para los colocativos hacer y tener.

21 También Dubský (1990a: 33) demuestra que dar, hacer y tener son los colocativos más usados, pero considera que el uso de hacer supera al de tener.

22 Hemos puesto la solución al ejercicio al final de cada oración, entre paréntesis. En el original (Lázaro Carreter, 1980: 203), el estudiante debe seleccionar el verbo más adecuado entre los que se le ofrecen en una lista. Nótese que tener en todas las ocurrencias en (4) funciona como verbo colocativo. 
léxico hasta tal punto que sólo conservan una parte de su significado muy general y taxonómica que remite al tipo semántico del verbo en cuestión ${ }^{23}$. Así, dar y hacer preservan el significado de 'acción' y tener, el de 'estado', 'tener una propiedad' ${ }^{24}$. Podemos advertir que este significado general está en correlación con la clasificación semántica de los nombres (véase la Tabla 2): dar se combina con una acción (paseo) y cuatro actos (beso, golpe, orden y permiso); hacer coocurre con dos acciones (viaje y uso), dos actos (broma y promesa) y una actividad (limpieza); y tener, con una actitud (respeto), tres estados (sueño, tos y sospecha) y un acontecimiento (susto).

Entre estos verbos de apoyo «puros» se encuentran también poner, tomar o estar (+ preposición); sin embargo, hemos escogido dar, hacer y tener siguiendo el criterio de que los nombres seleccionados coocurran exclusivamente con uno de los verbos, sin posibilidad de intercambio entre ellos. Así, si hubiésemos tenido en cuenta también el colocativo estar y nombres como huelga o gripe tendríamos que averiguar además qué colocación es más básica, o primitiva: estar de huelga o hacer huelga; estar con gripe o tener gripe; lo mismo sucedería en el caso de hacer una foto y tomar una foto. En este sentido, los nombres que seleccionan dar no admiten tener o hacer, los que coocurren con tener no aceptan dar ni hacer y del mismo modo, los que se combinan con hacer no van con dar ni tener.

\section{Algunas diferencias entre las construcciones con verbo de apoyo y sus correlatos verbales simples}

En general, los estudios que tratan de las CVA se centran fundamentalmente en la naturaleza de los verbos colocativos y la especial relación que se establece entre el colocativo y la base de la colocación, tratando de encontrar respuestas a través de su comparación con construcciones libres de verbo + sintagma nominal, por un lado, y no libres como las locuciones verbales, por otro ${ }^{25}$. Sin embargo, son pocos los autores que se han ocupado en profundidad de la relación entre la CVA y su contrapartida verbal libre y cuando lo han hecho ha sido para referirse a su natural afinidad. Así, se ha hablado de la relación verbo simple-CVA como de una característica inherente al sistema del español:

La falta de verbo simple correspondiente no representa sino un vacío en el inventario léxico del español, vacío que puede llenar precisamente la colocación funcional (o verbo complejo). (Koike, 2001:80)

\footnotetext{
23 Alonso Ramos (2004: 85-96) analiza el carácter vacío de los verbos de apoyo y propone una clasificación de los mismos de acuerdo con el grado de vaciedad semántica que presenten. Así, la autora distingue entre VERBOS DE APOYO «PUROS» como hacer, dar, tomar, etc; VERBOS DE APOYO CON COMPONENTES SEMÁNTICOS COMUNES A SUS CONTRAPARTIDAS LIBRES como gozar (de salud), que conserva el sentido 'agradable'; vERBOS DE APOYO SIN CONTRAPARTIDA LIBRE COMO cometer (un crimen); VERBOS DE APOYO CON UNA CONTRAPARTIDA LIBRE HOMÓNIMA como librar (una batalla); y VERBOS DE APOYO SEMÁNTICAMENTE PLENOS como decir (un piropo).

24 Según Dubský (1984), estos verbos sólo tienen una función de explicitación que se hace patente al eludirlos (Los paseos que daban por la tarde eran muy agradables = Los paseos de la tarde eran muy agradables). El mismo autor, en un trabajo posterior, añade que «a pesar de su significado explicitativo, el verbo pierde su función de expresar una relación, una cualidad, decayendo su uso a la de una partícula de relación» (Dubský, 1990b: 109).

25 Véase por ejemplo Koike (2001: 29-36). A las CVA, Koike las llamó primero verbos compuestos (1993, 1998) y luego verbos complejos (2001: 68) por su equivalencia precisamente a los verbos simples.
} 
Y su mutua equivalencia se acepta de forma generalizada, hasta tal punto que la relación entre ambas expresiones se ha utilizado como criterio para probar que estamos ante un tipo de verbos especiales (los colocativos):

El criterio más claro para identificar qué verbos pueden serlo de apoyo consiste en verificar si gracias a ellos se puede construir un sintagma $(<$ verbo de apoyo + sintagma nominal $>)$ equivalente a un verbo sencillo de la lengua. (Piera y Valera, 1999: 4415-16)

Así pues, parece que existe cierta unanimidad en la consideración de que las colocaciones verbo-nominales son las formas analíticas de los verbos plenos y entre ellas no hay diferencias semánticas cuando los verbos colocativos se vacían de su significado léxico original como es el caso de dar, hacer, tener, poner, tomar, etc., en dar un consejo, hacer mención, tener una duda, poner freno, tomar una decisión, etc. En cambio, cuando los colocativos conservan parte de su significado no existe tal equivalencia. Se trata en este caso de lo que algunos autores denominan «extensiones aspectuales» (Piera y Valera, 1999: 4418), «colocaciones aspectuales y léxicas» (Koike, 2001) o «verbos soporte ampliados» (Miguel, 2007) ${ }^{26}$.

En contraste con las opiniones anteriores, es interesante reproducir aquí el comentario de Miguel acerca de la relación entre CVA y verbos plenos, a pesar de que la autora no se ocupa expresamente de esta relación:

No resulta difícil encontrar casos en los que la expresión con verbos soporte no equivale al verbo por el que a primera vista se puede parafrasear (dar un corte, dar una sorpresa, hacer una llamada, tener una idea o tener un proyecto no son intercambiables en todos los contextos con sus correspondientes paráfrasis cortar, sorprender, llamar, idear o proyectar). Así, el hecho de que el médico haga un corte en el brazo del paciente no implica que el médico corte el brazo del paciente... (Miguel, 2006: 1299-1300).

En lo que sigue vamos a demostrar que en efecto existen diferencias entre las CVA y sus correlatos verbales simples. A partir del análisis de nuestros datos clasificaremos estas diferencias en tres grupos: las que afectan regularmente a la relación entre CVA y sus contrapartidas verbales libres (4.1), las que dependen de la clase semántica de las UULL (4.2) y, las que se deben a las características particulares de las UULL (4.3).

\subsection{Diferencias generales entre la construcción con verbo de apoyo y su contrapartida verbal libre}

En lo que concierne a las diferencias que afectan regularmente a la relación entre un verbo y su nombre deverbal acompañado de un verbo de apoyo podemos señalar las siguientes:

1) En general, el verbo pleno tiene un significado que abarca más contextos que el de la colocación. Dos son los casos más frecuentes: en primer lugar, el verbo puede ser un vocablo polisémico y la colocación restringirse a una de sus acepciones. Así, de los sentidos de USAR

26 Dentro de la LEC, aparte de los verbos de apoyo, que se consideran valores de la FL Oper ${ }_{1}$, existen muchos otros tipos de colocativos verbales, por ejemplo, verbos fasales - entablar, sostener (una conversación), abandonar (una carrera)-, causativos -suscitar (envidia), dispensar (una falta), sofocar (una rebelión)-, de realización -saldar (una deuda), obedecer (una orden)-. (véase Alonso Ramos, 2004) 
que ejemplificamos en (5), en donde significa 'hacer servir para un fin concreto'(5a), 'llevar puesto habitualmente' (5b) y 'sacar provecho de algo en un momento determinado' (5c)

(5) a. La leche rara vez se consume fresca, pero se usa para yogurts y quesos. (CREA)

b. [...] tiene 40 años aunque aparenta bastantes menos, usa gafas y lleva un año en Ruanda. (CREA)

c. Se vio obligado a usar todo su arte de orador didáctico para convencer a los jeques saharauis... (CREA)

sólo usar en (5c) es reemplazable por hacer uso: Se vio obligado a hacer uso de todo su arte de orador didáctico para convencer... En segundo lugar, una de las acepciones del verbo (o la única) puede hacer referencia a dos realidades extralingüísticas dando origen al fenómeno de la vaguedad léxica. El caso de golpear es una prueba de ello. Lo golpeó remite tanto a una única acción, pudiendo entonces parafrasearse por medio de la colocación dar un golpe en singular, como a una acción iterativa y en ese caso equivale a la colocación en plural dar golpes. En este sentido, Golpeó la puerta dos veces puede parafrasearse como 'X le dio dos golpes a la puerta uno detrás de otro' o bien 'X le dio varios golpes a la puerta en dos momentos diferentes'.

2) Usando el verbo pleno se puede especificar cómo es la acción o actividad en su totalidad (El conferenciante tose discretamente (CREA)/ [...] tose con discreción $\left.{ }^{27}\right)$, en cambio, con la CVA se precisa cómo es el acto, acción o estado en concreto (El conferenciante tiene una tos discreta $)^{28}$. Además de caracterizar el acto, acción o estado con más detalle, la CVA puede determinar cuántos actos son (Le dio un beso, dos besos...) o de qué tipo (Se dieron un beso de tornillo/de saludo/fraternal).

Conviene notar que no siempre es posible sustituir el adjetivo que acompaña al nombre predicativo en la CVA por el correspondiente adverbio en -mente modificando al correlato verbal simple. A través de algunos ejemplos específicos, podemos comprobar que las generalizaciones a este respecto resultan arriesgadas. Así, el adjetivo largo en [...] sugirió que dieran un largo paseo por la playa (CREA) hace referencia tanto al espacio que se recorre como al tiempo que se emplea para ello; sin embargo, el adverbio largamente en [...] paseamos largamente por la Playa de las Catedrales... ${ }^{29}$ parece referirse sólo al tiempo empleado en pasear y no al espacio recorrido (véase la nota 48). A pesar de que algunos adjetivos como cariñoso en Le dio un golpe cariñoso en la espalda..$^{30}$ y los adverbios en -mente correspondientes como cariñosamente en [...] la golpeó cariñosamente en un brazo ${ }^{31}$ parecen tener el mismo sentido, a saber, ' $\mathrm{X}$ haciendo Y muestra su cariño a Z', no sucede lo mismo con

27 Internet: <http://www.ruralprimicias.com.ar/noticia-mari--mari--todos-somos-hermanos-todos-somos-iguales58.php> [04/08/2009]

28 Sobre este aspecto, comenta Wotjak (1998: 272): «Tales verbos compuestos, [...] admiten, por lo menos en parte, la especificación detallada del sustantivo integrante, al cual se le atribuye cantidad de adjetivos. Así se logra una concreción y especificación mayor de la predicación entera, la cual no podría obtenerse tan fácilmente, si se le añadieran adverbios al verbo paralelo.»

29 Internet: <http://cronicasmadrilenas.blogspot.com/2006_07_01_archive.html> [04/08/2009]

30 Internet: $<$ http://www.fanfiction.net/s/2617328/1/Algo_contigo $>$ [05/08/2009]

31 Internet: <http://maca-esther.mforos.com/561352/7047892-en-secreto/?marcar=buenas + noches\&pag=2> [05/08/2009] 
amable en Le gustaba hacer bromas amables entre nosotros... ${ }^{32}$ y amablemente en La Princesa bromea amablemente con el Rey... ${ }^{33}$ En el primer caso, amable se refiere al contenido de la broma ('que no ofende por su contenido'), en el segundo, a la actitud del que hace la broma ('X, mostrando amabilidad').

3) Generalmente, el verbo y el nombre predicativo poseen el mismo número de actantes semánticos: uno en $X$ tose y la tos de $X(6)$; dos en $X$ usa $Y$ y el uso de $X$ de $Y(7)$; tres en $X$ permite $Y$ a $Z$ y el permiso de $X$ de $Y$ a Z (8), etc.:

(6) a. El barbero tose. (CREA)

b. La tos del barbero

(7) a. $[\ldots]$ cada mago usa sus trucos... ${ }^{34}$

b. El uso de cada mago de sus trucos

(8) a. [...] el director permite salir del centro a varios reclusos... ${ }^{35}$

b. El permiso del director de salir del centro a varios reclusos

En su expresión sintáctica, sin embargo, algunos de los actantes del nombre y el nombre mismo pasan a ser dependientes del verbo apoyo. Así, en todos los ejemplos de (9), el actante semántico $\mathrm{X}$ del nombre pasa a desempeñar el papel de sujeto gramatical de los verbos de apoyo; cuando el nombre tiene dos actantes, Y puede continuar dependiendo del nombre, como uso en (9b) o pasar al verbo ${ }^{36}$; por último, si el nombre tiene tres actantes como permiso en (9c) Y queda como dependiente del nombre y $\mathrm{Z}$ pasa al verbo:

(9) a. El barbero tiene tos.

b. Cada mago hace uso de sus trucos.

c. El director da permiso de salir del centro a varios reclusos.

4) La estructura comunicativa de un enunciado con un verbo simple y la de uno con una CVA son diferentes. Dentro de la TST, una estructura comunicativa es aquella que se superpone a la estructura semántica, representada en forma de red con nodos (Mel'čuk, 2001). Si la estructura semántica da cuenta del contenido proposicional de un enunciado, la comunicativa organiza ese contenido de acuerdo con una serie de dimensiones. Los enunciados de (10) presentan la misma estructura semántica, pero su estructura comunicativa difiere en lo que respecta a dos dimensiones: la tematización o división de un enunciado en Tema y Rema, y la unidad o separación de los nodos que integran la red semántica.

(10) a. Lula viaja a Cuba... ${ }^{37}$

b. Lula hace un viaje a Cuba.

32 Internet: $<$ http://www.jakecolsen.com/Translations/Spanish/Jake-spanish.pdf $>$ [05/08/2009]

33 Internet: $<\mathrm{http}: / /$ www.todocine.com/mov/00215446.htm> [05/08/2009]

34 Internet: <http://forum.goalunited.org/archive/index.php/t-32716.html > [05/08/2009]

35 Internet: $<$ http://www.cndh.org.mx/recomen/1992/151.htm > [05/08/2009]

36 Cfr. Pedro tiene miedo de Martín, donde Martín depende de miedo y Pedro le tiene miedo a Martín, en que Martin depende de tener.

37 Internet: <http://www.soitu.es/soitu/2008/10/30/info/1225400158_570809.html> [05/08/2009] 
En lo que concierne a la división en Tema y Rema, en este ejemplo deben distinguirse dos fases: la tematización primaria, idéntica para (10a) y (10b) como se representa en (11a), y la secundaria, que sólo tiene lugar en (10b) como se muestra en (11b).

(11) a.

\begin{tabular}{|c|c|}
\hline TEMA 1 & REMA 1 \\
\hline Lula & $\begin{array}{c}\text { viaja a Cuba } \\
\text { hace un viaje a Cuba }\end{array}$ \\
\hline
\end{tabular}

b.

\begin{tabular}{|c|c|c|}
\hline TEMA 1 & \multicolumn{2}{|c|}{ REMA 1 } \\
\hline \multirow{2}{*}{ Lula } & TEMA 2 & REMA 2 \\
\cline { 2 - 3 } & hace & un viaje a Cuba \\
\hline
\end{tabular}

Cuando la estructura semántica no está marcada con una tematización secundaria, los nodos son tratados en bloque, es decir, lexicalizan en una UL (viajar). Por el contrario, si hay tematización secundaria, los nodos se conciben por separado y lexicalizan en UULL diferentes (hacer, viaje). El elemento lexicalizado o incorporado dentro de viajar ('viaje') es información de fondo para el hablante, sin embargo, cuando constituye una UL independiente pasa a un primer plano informativo. Dentro de un análisis efectuado dentro del marco lexemático-funcional, se llega a una conclusión semejante. Así, Martín Mingorance (1998: 22) advierte que «al pasar la carga semántica de las unidades sintagmáticas verbales al sustantivo, éste se convierte en el foco o portador de información nueva».

\subsection{Diferencias basadas en la clase semántica de las unidades léxicas}

Las diferencias que hemos encontrado entre las CVA y sus correlatos verbales simples están muy lejos de formar un conjunto completo debido a que las limitaciones de nuestro corpus nos impiden extraer generalizaciones mayores. En consecuencia, presentaremos unas observaciones que atañen: 1) a los verbos de apoyo, 2) a la relación entre verbos de lengua y CVA y, 3) a la relación entre verbos de contacto físico y CVA.

1) Una importante restricción para la equivalencia completa entre los verbos plenos y las CVA viene determinada por los verbos de apoyo. Hemos observado que ni dar, ni hacer, ni tener, los tres verbos de apoyo seleccionados en nuestro corpus, admiten un sujeto que no sea humano. Así, mientras que en los ejemplos de (12), los verbos plenos aceptan sujetos no humanos,

(12) a. La luz se filtraba por las contraventanas y el viento golpeaba en ellas. (CREA)

b. [...] bebieron del jarabe en silencio, como ordenaba el ritual. (CREA)

c. [...] el Parlamento alemán aprobó una ley que permitía a los ciudadanos... (CREA)

d. La luz no viaja tan rápida como la pintan ${ }^{38}$.

e. [...] porque el agua sanea, limpia los pecados, el cuerpo y el alma. (CREA)

f. [...] la actitud del caracol que es un animal que camina lento y que se asusta de un entorno que siempre cree hostil. (CREA) 
g. La malla vegetal respetaba escrupulosamente las ventanas... (CREA)

comprobamos que sus correspondientes formas analíticas con los colocativos dar, hacer y tener (13) no son posibles:

(13) a. *La luz se filtraba por las contraventanas y el viento daba golpes en ellas.

b. *[...] bebieron del jarabe en silencio, como daba orden el ritual.

c. *[...] el Parlamento alemán aprobó una ley que daba permiso a los ciudadanos...

d. *La luz no hace viajes tan rápidos...

e. $*[\ldots]$ porque el agua sanea, hace limpieza de los pecados, del cuerpo y del alma.

f. [...] *la actitud del caracol que es un animal que camina lento y que tiene sustos de un entorno que siempre cree hostil.

g. *La malla vegetal tenía respeto escrupuloso por las ventanas...

Este fenómeno ya ha sido notado por otros autores como Piera y Valera (1999: 4416), quienes llaman la atención, por ejemplo, acerca de la diferencia entre reposar y hacer reposo: «hacer con sujeto humano parece conservar suficiente sentido agentivo como para impedir *Aquí hacen reposo los restos mortales de X.» También Miguel (2007: 305) advierte que «el sujeto de los verbos soporte ha de estar especificado para el rasgo [+ humano]». Esta autora da un paso adelante manifestando sus dudas acerca de la vaciedad completa de significado léxico de los verbos de apoyo y sugiriendo que la selección del sujeto no corresponda exclusivamente al nombre predicativo.

2) Dentro del conjunto de datos analizados, también la relación entre los verbos de lengua y las colocaciones equivalentes parece presentar unas características particulares. Con la excepción de bromear, que es intransitivo y no permite especificar el contenido de la broma por medio de un complemento, los demás, ordenar, permitir y prometer, se construyen con un OD que hace explícita la cosa dicha -la orden, el permiso y la promesa, respectivamente-. Este OD -con los verbos plenos-adopta la forma de un sintagma nominal (14a), una oración de infinitivo (15a) o bien una oración subordinada sustantiva introducida por la conjunción que (16a). La misma característica se mantiene cuando el verbo pleno se sustituye por una CVA, con la salvedad de que aquí no se trata de OD del verbo principal sino de un objeto dependiente del nombre predicativo. Véanse los ejemplos (14b), (15b) y (16b) ${ }^{39}$.

(14) a. La hermana María de los Serafines ordena la búsqueda del dedo cercenado. (CREA) b. [...] no se le ve por aquí, desde que la Policía dio una orden de busca y captura contra él... (CREA)

(15) a. [...] su ajustada agenda sólo le permitía pasar una tarde en el pueblo... (CREA)

b. También el padre le daba permiso para fumar en su presencia... (CREA)

(16) a. Antes de morir, tu madre me hizo prometer que nunca te hablaría de la guerra... (CREA)

b. [...] aunque el Gobierno hizo la promesa de que al finalizar el cuatrienio... (CREA)

39 Entre los nombres predicativos -orden, permiso y promesa-y sus correspondientes complementos es necesario añadir la preposición de, (14b) y (16b), o para, (15b). 
Sin embargo, la CVA, a diferencia de los verbos plenos, permite la no explicitación del contenido del objeto, poniendo énfasis únicamente en la existencia del mismo -compárese (17a) y (18a) con (17b) y (18b), en donde es necesario al menos dejar una huella pronominal del objeto ${ }^{40}$.

(17) a. Diego en cambio, claro, es un tío y cuando un tío da una orden, se cumple a rajatabla. (CREA)

b. Diego en cambio, claro, es un tío y cuando un tío ordena *(algo), se cumple a rajatabla.

(18) a. Le miré. Me sonrió. Me daba permiso. (CREA)

b. Le miré. Me sonrió. Me *(lo) permitía.

Por el contrario, parece que los verbos plenos son los únicos que tienen la capacidad de construir enunciados performativos. Examinemos los ejemplos (19) y (20):

(19) a. [...] les ordeno que guarden silencio $^{41}$.

b. Les doy la orden de que guarden silencio.

(20) a. [...] prometo serte fiel en lo próspero y en lo adverso, en la salud... (CREA)

b. Te hago la promesa de serte fiel en lo próspero y en lo adverso, en la salud... ${ }^{42}$

En (19a) y (20a), con el verbo en primera persona de singular, el hablante está realizando un acto de habla en el momento de la enunciación, sin embargo en (19b) y (20b), con las correspondientes CVA, el hablante sólo describe el acto realizado.

En el caso de permitir (Está bien, te permito salir ${ }^{43}$ ) y dar permiso (Hala, te doy permiso para que pises el césped en los entrenamientos... ${ }^{44}$ ), parece que la CVA tiene también valor performativo. La razón tal vez haya que buscarla en el verbo de apoyo dar o bien en la clase semántica más específica del nombre, puesto que también dar autorización, licencia funcionan del mismo modo. Obsérvese que estos nombres - permiso, autorización, etc.- cuando se construyen con artículo y/o en plural adoptan el sentido de 'escrito en el que se consigna el

40 La CVA permite también la cuantificación de los objetos -es decir, el plural de los objetos implica más de una unidad y no significa 'intensidad' como ocurre con el nombre continuo esperanza en Llegamos con muchas esperanzas, tranquilos y confiados (CREA)-, por ejemplo en [...] vamos a recordar algunas de las promesas que hicieron, y que se han ido quedando por el camino (CREA). Así mismo, es posible calificar el objeto, Dieron órdenes estrictas, verbales, etc. y no la acción como en Ordenaron estrictamente, verbalmente, etc. Consideramos, no obstante, que estas características son de carácter general y quedarían comprendidas ya en el punto 2 del apartado 4.1.

41 Internet: <http://www.scribd.com/doc/6808873/Figueroa-Alberto-Sultana-Roja> [05/08/2009]

42 Podría objetarse que en algún contexto, sería posible interpretar Te hago la promesa de serte fiel... como un enunciado performativo, además de descriptivo; aún en este caso, creemos que el grado de performatividad es mucho menor que en Prometo serte fiel... Véase González Ruiz (2006) para una discusión de la performatividad como propiedad gradual.

43 Internet: <http://www.pikaflash.com/foros/archive/index.php/t-139025.html> [05/08/2009]

44 CREA 
permiso/autorización', por ejemplo, [...] si en el permiso dice «válido para un viaje» es sólo por uno... ${ }^{45}$

3) Los dos verbos de contacto físico que aparecen en el corpus (golpear y besar) presentan una particularidad con respecto a la CVA (dar un golpe/dar un beso $)^{46}$. Así, tanto uno como otro, además de presentar las formas proposicionales básicas que se ilustran en (21) y (22), en donde se especifica la parte del objeto que se golpea o besa por medio de un sintagma introducido por la preposición en,

(21) a. [X golpea (a) Y en Z con W]

$\mathrm{X}$, siendo un individuo; $\mathrm{Y}$, una entidad; $\mathrm{Z}$, una parte de la entidad; $\mathrm{W}$, un instrumento.

b. [...] golpeó a Vélez en la cara con la mano abierta... (CREA)

(22) a. [X besa a Y en Z]

$\mathrm{X}$, siendo un individuo; $\mathrm{Y}$, un ser animado; $\mathrm{Z}$, una parte del cuerpo de $\mathrm{Y}$.

b. Pone el brazo alrededor de su cintura y la besa en la frente... (CREA)

pueden construirse focalizando la parte del objeto de tal modo que esta parte representa la totalidad del mismo. Obsérvese el contraste que ese produce entre (23a) y (23b) y entre (24a) y (24b):

(23) a. Una sombra femenina golpea en los cristales de la puerta. (CREA)

b. Una sombra femenina golpea los cristales de la puerta.

(24) a. [...] la besó en los labios. (CREA)

b. [...] le besó los labios... (CREA)

En (23a) y (24a), los cristales y los labios son claramente una parte de algo - una puerta, en (23a) - o alguien -en (24a)-; en cambio, en (23b) y (24b), ambos objetos se conciben como una unidad o un todo. El contraste entre ambas expresiones viene marcado por las diferentes funciones sintácticas que desempeña la parte del objeto Z. En (23a) y (24a) Z aparece construido en forma de complemento locativo introducido por la preposición en. Nótese que en el $D U E$, el sentido básico de esta preposición es 'expresar el lugar dentro del cual está u ocurre la cosa de que se trata'. Sin embargo, en (23b) y (24b), Z funciona como primer objeto verbal u OD.

Además de las propiedades comunicativas y sintácticas señaladas, también pueden apreciarse matices semánticos que diferencian ambas expresiones. Así, mientras que en la oración (25), los golpes en el portalón de madera son un medio para conseguir algo, a saber, para llamar la atención de alguien que esté al otro lado del mismo, los golpes a las paredes de (26) constituyen una finalidad en sí misma.

(25) [...] se dirigió a un portalón de madera y golpeó en él con el mango de la fusta. Al cabo de unos instantes una mirilla dejó salir un tajo de luz al descorrerse. (CREA)

45 Internet: <http://losyoruguas.com/permiso-del-menor/> [05/08/2009]

46 A pesar de la coincidencia de que ambas CVA se construyan con el colocativo dar, no podemos hacer una generalización a ese respecto, pues otros nombres de contacto físico como caricia seleccionan el verbo de apoyo hacer. 
(26) $[\ldots]$ a veces lloraba o golpeaba las paredes como un loco... (CREA)

En (27) y (28) observamos que se mantienen las mismas diferencias al utilizar la CVA correspondiente:

(27) [...] se dirigió a un portalón de madera y dio unos golpes en él con el mango de la fusta. Al cabo de unos instantes una mirilla dejó salir un tajo de luz al descorrerse.

(28) $[\ldots]$ a veces lloraba o daba golpes a las paredes como un loco...

Sin embargo, cuando la entidad golpeada es una persona, las distinciones semánticas quedan neutralizadas en la CVA. Así, en (29),

(29) [...] Desde dentro de la armadura se le oye gemir. Sancho lo golpea en el pecho [a don Quijote] como si diera con los nudillos en una puerta) Eh, eh, ¿qué tal anda por ahí dentro? (CREA)

al expresar el verbo golpear con un OD de persona -lo, [a don Quijote]- y la parte del cuerpo golpeada con un sintagma preposicional encabezado por en, una interpretación muy posible es que los golpes sean el medio que Sancho utiliza para obtener una respuesta de don Quijote y saber si éste se encuentra bien dentro de la armadura. En cambio, en (30),

(30) Me abrazaba, me golpeaba la espalda: «Quién diría que tú eres aquí el botones...» (CREA)

en donde es la parte del cuerpo la que funciona como OD de golpear y la persona como OI, los golpes sirven a modo de saludo afectuoso. La CVA, por el contrario, sólo admite una diátesis: la expresión de la parte del cuerpo por medio de un sintagma preposicional con en (31):

(31) a. Sancho le da golpes a don Quijote en el pecho.../*Sancho le da golpes al pecho de don Quijote...

b. Me daba golpes en la espalda...**Le daba golpes a mi espalda.

Una diferencia semejante es la que se establece en los ejemplos de besar. En (32),

(32) Alberto besó fugazmente a Cecilia en los labios. (CREA)

cuando la parte del cuerpo se expresa por medio de un sintagma preposicional encabezado por en, la persona a la que se besa aparece en una posición central, con la función de OD. La parte del cuerpo añade información adicional, por ejemplo, de qué clase de beso se trata (pasional, de saludo, etc.), cómo es la relación que mantienen, o tratan de alcanzar, los que se besan (amistosa, amorosa, paternal, etc.). Por el contrario, si la parte del cuerpo desempeña la función de OD, desplazando a la persona que se besa a un segundo plano -lo que ocurre en (33)-, se produce una distancia emocional con la persona. De este modo, no se informa 
acerca de la relación que une a las personas sino acerca de la acción misma de besar y de las características particulares de la parte del cuerpo que se besa ${ }^{47}$.

(33) [...] me besó sin querer la comisura de los labios... (CREA)

Los matices semánticos que presenta el verbo besar desaparecen si utilizamos la correspondiente CVA. Así por ejemplo, tanto (32) y (33), expresados como CVA en (34a y b) permanecen ambiguos en sus formas analíticas, a menos que se dé información adicional que matice los sentidos ${ }^{48}$.

(34) a. Alberto le dio un beso fugaz a Cecilia en los labios.

b. Me dio sin querer un beso en la comisura de los labios.

\subsection{Diferencias basadas en las características particulares de las unidades léxicas}

En este apartado comentaremos algunas de las particularidades concretas que diferencian a unos verbos plenos de sus correspondientes CVA, centrándonos en los verbos mismos y en los nombres que constituyen la base de las colocaciones. Con esta descripción no agotamos todos los matices que distinguen unas expresiones de otras, únicamente ofrecemos una muestra representativa, obtenida a partir de nuestros datos.

En contra de la regla general, enunciada más arriba ${ }^{49}$, según la cual los verbos plenos tienen un sentido más amplio que el de las colocaciones correspondientes, hemos encontrado una excepción en el corpus. Se trata del verbo de lengua bromear y su correlato hacer una broma. En este caso, hacer una broma tiene un sentido más amplio, pues se aplica no sólo a las bromas que se manifiestan oralmente como es el caso de bromear, sino que se extiende a todo tipo de bromas. Puede observarse además que ambas expresiones presentan diferentes formas proposicionales. El nombre broma consta de tres actantes semánticos: broma de persona $X$ a persona $Y$ a propósito de propiedad, estado o acción $Z$, que se mantienen en la CVA (35). Sin embargo, con bromear, el actante semántico Y no puede expresarse sintácticamente (36).

(35) El hijo mayor [X] -ya un hombre- me [Y] hizo una broma pesada en relación a las mujeres $[\mathrm{Z}] \ldots(C R E A)$

(36) Matías Guiu $[\mathrm{X}]$ bromea sobre cuestiones existenciales $[\mathrm{Z}]$ en su primer libro en catalán. (CREA)

\footnotetext{
47 Nótese que besar los pies (de alguien) es una locución verbal que se emplea como fórmula ceremoniosa de cortesía, dirigida por un hombre a una mujer, de escaso contenido emocional.

48 En este apartado, podrían tratarse también los pares de verbos plenos y colocaciones que designan desplazamiento físico como pasear y dar un paseo o viajar y hacer un viaje, pero no disponemos de suficientes muestras para hacer generalizaciones. Es interesante, no obstante, observar cómo paseo admite complementos de medida de espacio que son rechazados, en cambio, por pasear (La rusa Olga Kaniskina se dio un paseo triunfal de 20 kilómetros (Internet: <http://www.galdakaoat.com/euskadi/766-paseo-triunfal-de-kaniskina-maria-vasco-quinta> [06/08/2009])/*Paseó $20 \mathrm{kms}$.).

49 Véase el punto 1 del apartado 4.1.
} 
Una niña en (37a) no representa al actante Y puesto que la niña no es la persona hacia la que se dirige la broma sino con la que se comparte la misma, hecho que se comprueba con más claridad en (37b) en relación a séquito:

(37) a. Kiko bromea con una niña por las calles de Belgrado. (CREA)

b. [...] salió de palacio riendo y bromeando con su séquito acerca de las ínfulas del clero, de sus apabullantes desayunos... (CREA)

Un caso opuesto en extremo al que acabamos de señalar es el del par limpiar y hacer (la) limpieza. El sentido del verbo pleno -'X quita de Y las sustancias u objetos que sobran'- cubre situaciones tan variadas como las que se muestran en (38).

(38) a. [...] un vecino que baja con su hijo se dedica a limpiar el parque. (CREA)

b. [...] a la única que le permitía acercarse a su hogar era a una compatriota suya que venía a limpiar su piso... ${ }^{50}$

c. Se quitó las gafas y las limpió con el pañuelo. (CREA)

d. [...] mientras limpiaba con la servilleta de papel las gotas de café... (CREA)

e. Un pocero fallece mientras limpiaba una alcantarilla de Madrid. (CREA)

f. La madre cambiaba y limpiaba al bebé en la fuente de la Puerta del Sol... (CREA)

De ellas, tan sólo (38b) puede ser reemplazada por hacer la limpieza -O quizá fuese la mujer que venía a hacer la limpieza del piso (CREA)-, cuyo sentido aproximado sería el de 'mantener limpio un espacio interior que se usa como vivienda o lugar de trabajo'. De ahí que no se pueda hacer la limpieza de exteriores, de objetos pequeños o de un bebé, entre otros ${ }^{51}$.

Otro par verbo-CVA que merece un comentario aparte es el constituido por sospechar y tener $(l a)$ sospecha $(s)$. En líneas generales, el nombre sospecha tiene dos acepciones muy cercanas que parafraseamos del siguiente modo: 'creencia de la persona $\mathrm{X}$ de la existencia del hecho Y basada en indicios' y 'creencia de la persona X de que la persona $\mathrm{Y}$ ha hecho algo; tal creencia está basada en indicios ${ }^{52}$. La primera acepción, que representamos como sospechala, se corresponde con el verbo pleno sospecharla (X sospecha que $Y$ ) y aparece en la CVA tener la sospecha o tener sospechas (X tiene la sospecha de que YIX tiene sospechas de que Y). La segunda acepción, sospechalb, está en relación con sospechar $1 b$ ( $X$ sospecha de Y) $\mathrm{y}$, a su vez, remite a la CVA tener una sospecha o tener sospechas (X tiene una sospecha de Y/X tiene sospechas de Y). En (39a y b) y (40a y b), comprobamos la correspondencia entre las formas verbales y las colocaciones, respectivamente.

(39) a. La mayoría te tiene por un sinvergüenza y nadie sospecha que ignorabas la verdad. $(C R E A)$

50 Internet: $<$ http://www.dosdoce.com/continguts/res_libros/vistaSola_cas.php?ID=184> [06/08/2009]1

51 También permitir y dar permiso se encuentran en una situación similar a la de limpiar y hacer (la) limpieza, hasta tal punto que consideramos que dar permiso se acerca más a autorizar, en su sentido básico de 'declarar una persona con autoridad que otra puede hacer algo', que a permitir 'no oponerse a que se haga algo'.

52 Podríamos considerar que se trata de un único sentido con dos componentes semánticos disyuntivos: 'creencia de la persona $\mathrm{X}$ de la existencia del hecho $\mathrm{Y}$ o de que la persona $\mathrm{Y}$ ha hecho algo; tal creencia está basada en indicios'. Hemos optado por dos sentidos separados basándonos en la existencia de dos estructuras de actantes diferentes. 
b. La mayoría te tiene por un sinvergüenza y nadie tiene la sospecha de que ignorabas la verdad.

(40) a. [...] el pensar que la gente puede sospechar de ti es una cosa terrible, sobre todo en una cosa así, ¿no?... (CREA)

b. [...] el pensar que la gente puede tener alguna sospecha de ti es una cosa terrible, sobre todo en una cosa así, ¿no?...

Una de las diferencias que presentan ambos pares (verbo y CVA) estriba en que el nombre de las CVA admite la variación en número (véase (41a y b)). De este modo, cuando la CVA lleva el nombre en plural se indica que existen varios indicios para fundamentar la creencia. Con el verbo derivado, en cambio, no es posible cuantificar los indicios ${ }^{53}$.

(41) a. ¿Pero usted los acusa directamente o tiene sospechas de que forman parte de entramado gubernamental? (CREA)

b. Pero ya el hecho de que empiecen a tener sospechas de mí, me digan que no puedo hablar con las alumnas, era señal de que estaban pensando algo. (CREA)

Por último nos referiremos a los pares asustarse y tener un susto, de un lado, y toser y tener tos, de otro, que constituyen casos especiales por sus diferencias de carácter aspectual. Asustarse es un verbo incoativo, es decir, susceptible de focalizar el proceso en cada una de sus fases -inicial (Está a punto de asustarse/Se va a asustar), media (Se está asustando) y final (Está completamente asustado)-; en cambio, tener un susto denota únicamente la fase final del proceso (Tiene un susto de muerte). En lo que se refiere al par toser y tener tos, puede decirse que el primero tiene un sentido más amplio que el segundo. Así, en muchos casos toser (42b) puede cubrir usos de tener tos (42a), pero no a la inversa-tener tos (43b) no puede sustituir a toser (43a)-.

(42) a. La gente con asbestosis tiene dificultad para respirar, a menudo tiene tos, y en casos graves sufre dilatación del corazón ${ }^{54}$.

b. La gente con asbestosis tiene dificultad para respirar, a menudo tose, y en muchos...

(43) a. Se detenía a toser, disimulando el acceso, como quien sufre el asalto de algún pariente vergonzante. (CREA)

b. *Se detenía a tener tos, disimulando el acceso, como quien sufre...

53 El matiz aportado por el nombre en plural es cercano, si bien no idéntico, al que proporciona el adjetivo colocativo fuerte acompañando a sospecha: una sospecha fuerte es aquella que se basa en la certeza de los indicios, y no exactamente en su número -[...] tienen fuertes sospechas de que Irán, Corea del Norte, Libia, Sudán y Siria han desarrollado programas de armas bacteriológicas (CREA)-. Obsérvese que esta información es diferente de la que aportan los adjetivos grave y serio combinados con sospecha: una sospecha grave o seria es aquella en la que el hecho ocurrido o lo que $\mathrm{Y}$ ha hecho tiene consecuencias muy dañosas. Véase la entrada de sospecha en el DiCE (http://www.dicesp.com) y una explicación más detallada de los colocativos adjetivales de sospecha en Alonso Ra$\operatorname{mos}(2002: 88)$.

54 Internet: http://www.abogada.com/abogados/asbestos/mesotelioma/Fibras_de_Asbesto_Afecta_Los_Pulmones/> [06/08/2009] 
Ambas expresiones son válidas para expresar 'varios carraspeos seguidos en varios intervalos de tiempo regulares' (Tiene gripe y tose/Tiene gripe y tos); sin embargo sólo toser puede emplearse con el sentido de 'varios carraspeos seguidos en un intervalo de tiempo' (Durante la reunión tosió una vez/?Durante la reunión tuvo tos una vez). Este último componente de toser es el que habilita al verbo para expresar aspecto iterativo (44a), imposible con tener (tos) (44b), que es sólo susceptible de indicar la repetición de la acción completa en diferentes ocasiones $(44 \mathrm{c})$.

(44) a. [...] he pasado toda la noche tose que te tose $\mathrm{e}^{55}$.

b. ${ }^{*}[\ldots]$ he pasado toda la noche teniendo y teniendo tos.

c. Tiene tos una y otra vez.

En cualquier caso la diferencia aspectual más significativa entre ambas expresiones radica en que toser es un hecho dinámico y tener tos, un estado. Los estados en tanto que hechos continuos en el tiempo no pueden combinarse con las perífrasis ponerse $a+$ infinitivo ni parar de + infinitivo. Compárese toser en (45) con tener tos (46):

(45) a. La tía va y lo escupe y se pone a toser. (CREA)

b. [...] cogí a Miquel y me lo llevé a casa. No paraba de toser y se le veía consumido. $(C R E A)$

(46) a. *La tía va y lo escupe y se pone a tener tos.

b. [...] cogí a Miquel y me lo llevé a casa. *No paraba de tener tos y se le veía consumido.

Además del rasgo señalado, ambas expresiones se distinguen por el carácter voluntario y/o involuntario de la acción que designan. Así, mientras toser puede hacer referencia a una acción tanto voluntaria como involuntaria, tener tos sólo alude a una involuntaria. Prueba de ello es que sólo toser admite modalidad imperativa - Compárese (47) con (48) ${ }^{56}$.

(47) Sra. no tosa, por favor, no tosa ${ }^{57}$.

(48) *No tenga tos, por favor.

Por último, hemos advertido que tanto el verbo toser como el sustantivo tos contienen un componente semántico en sus definiciones que hace referencia al sonido que se produce al emitir el carraspeo. Es este componente el que posibilita que toser y tos coocurran con verbos de percepción auditiva. Compruébese así cómo toser se combina con oír en (49a), escuchar en (49b) y sentir en (49c) y tos con escuchar en (49d).

(49) a. Le oía toser en el baño por las mañanas... (CREA)

55 Internet: $<$ http://www.mundorecetas.com/8/viewtopic.php? $\mathrm{f}=2 \& \mathrm{t}=289470 \& \mathrm{st}=0 \& \mathrm{sk}=\mathrm{t} \& \mathrm{sd}=\mathrm{a}>[06 / 08 / 2009]$

56 El carácter volitivo o intencional de toser también queda patente en el ejemplo siguiente: Miguel se cansó de que preguntaran tantas cosas y empezó a toser para que se marcharan (CREA).

57 Internet: <http://ar.answers.yahoo.com/question/index?qid=20070721081942AAYtUIu> [06/08/2009] 
b. Porta escuchó toser al obispo y pensó en lo dura que debía de ser su existencia. (CREA)

c. ¿Qué pasa, señora? La sentí toser, y... ¿Qué le pasa? (CREA)

d. Durante el primer solo, a los 44 segundos, se escucha una pequeña tos, seguida de una corta aspiración a los 48 segundos. Se ha rumoreado que durante la grabación el hábito de fumador de Gilmour le hizo toser durante el solo y que renunció a este hábito cuando escuchó la tos durante la mezcla ${ }^{58}$.

Sin embargo, resulta curioso que el sustantivo tos cuando forma parte de la CVA no acepte la coocurrencia con dichos verbos (50). Ello nos hace pensar en que, de algún modo, el componente semántico 'producir sonido' de tos queda invalidado cuando se combina con tener. Esta circunstancia nos lleva de nuevo a cuestionarnos hasta qué punto el colocativo pierde su significado al unirse al sustantivo o bien hasta qué punto es el nombre el único responsable de la selección léxica.

(50) La *oyó (*escuchaba, *sintió) tener tos.

\section{Conclusiones}

En este estudio hemos analizado la relación entre quince colocaciones formadas por un verbo de apoyo y un nombre y los verbos simples correspondientes. Hemos tratado de mostrar que, pese a la tan mencionada equivalencia semántica entre ambas expresiones, dicha afirmación sólo se cumple en un nivel teórico, o ideal, pues, a medida que nos ocupamos de casos específicos surgen las diferencias. Hemos observado que en numerosos contextos, las formas analíticas y sus correlatos sintéticos no son mutuamente intercambiables. El objetivo de este trabajo ha sido el de clasificar las diferencias encontradas entre ambas expresiones en tres grupos: las que afectan regularmente a la relación entre CVA y sus correlatos verbales simples, las que dependen de la clase semántica de las UULL y las que son debidas a las características particulares de las UULL.

Lejos de ser exhaustiva, esta clasificación constituye una primera aproximación al fenómeno, que desarrollaremos en el futuro extendiendo el número y la clase semántica de los nombres y de los verbos colocativos. La finalidad del proyecto es obtener más generalizaciones que puedan tener interés gramatical -por ejemplo, lograr un mayor entendimiento de la naturaleza de los verbos colocativos y su relación con la base de la colocación- o deban ser consignadas en un diccionario, en concreto, en el DiCE. Ya en los años sesenta algunos autores (véase Mel'čuk y Žolkovskij, 1970; Mel'čuk, 1992, entre otros) señalaron la importancia de la paráfrasis lingüística no sólo para toda teoría lingüística sino también para la lingüística aplicada, por ejemplo, la traducción automática. Es, pues, una tarea pendiente el hacer explícitas todas las condiciones de aplicación para que dos expresiones puedan guardar una relación de sinonimia en sentido estricto. 


\section{Glosario de siglas}

CREA: Corpus de referencia del español actual, (véase el apartado Diccionarios y corpus).

CVA: construcción con verbo de apoyo

DEA: Diccionario del español actual (véase en Diccionarios y corpus)

$D E C$ : Dictionnaire explicatif et combinatoire (véase en Diccionarios y corpus)

DELE: Diccionario para la enseñanza de la lengua española (véase en Diccionarios y corpus)

DiCE: Diccionario de colocaciones del español (<www.dicesp.com> [26/06/2008])

DiCoInfo: Dictionnaire fondamental de l'information et de l'Internet (véase en Diccionarios y corpus)

DRAE: Diccionario de la lengua española (véase en Diccionarios y corpus)

DSLE: Diccionario Salamanca de la lengua española (véase en Diccionarios y corpus)

DUE: Diccionario de uso del español (véase en Diccionarios y corpus)

FDS: A Frequency Dictionary of Spanish (véase en Diccionarios y corpus)

FL (pl. FFLL): función léxica

$L A F$ : Lexique actif du français (véase en Diccionarios y corpus)

LEC: Lexicología explicativa y combinatoria

OD: objeto directo

RAE: Real Academia Española

REDES: Diccionario combinatorio del español combinatorio (véase en Diccionarios y corpus)

TST: Teoría sentido-texto

UL (pl. UULL): unidad léxica

\section{Referencias bibliográficas}

Alonso Ramos, M. (1994-1995): «Hacia una definición del concepto de colocación: de J. R. Firth a I. A. Mel'čuk», Revista de Lexicografía 1, págs. 9-28.

Alonso Ramos, M. (1997): «Coocurrencia léxica y descripción lexicográfica del verbo DAR: hacia un tratamiento de los verbos soportes», Zeitschrift für Romanische Philologie, 113:3, págs. 380-417.

Alonso Ramos, M. (2002): «Colocaciones y contorno de la definición lexicográfica», Lingüística Española Actual, 24:1, págs. 63-95.

Alonso Ramos, M. (2003): «Hacia un Diccionario de colocaciones del español y su codificación». En Martí, M. A., Fernández, A. y G. Vázquez (eds.): Lexicografía computacional y semántica. Barcelona, Edicions de la Universitat de Barcelona, págs. 11-34.

Alonso Ramos, M. (2004): Las construcciones con verbo de apoyo. Madrid, Visor Libros.

Alonso Ramos, M. (2005): «Semantic Description of Collocations in a Lexical Database». En Kiefer, F. et alii (eds.): Papers in Computational Lexicography COMPLEX 2005. Budapest, Linguistics Institute and Hungarian Academy of Sciences, págs.17-27.

Alonso Ramos, M. (2006): «Glosas para para las colocaciones en el Diccionario de Colocaciones del Español». En Alonso Ramos, M. (ed.): Diccionario y Fraseología. Coruña, Universidad de la Coruña, págs. 59-88.

Blasco Mateo, E. (2002): «La lexicalización y las colocaciones», Lingüistica Española Actual, 24:1, págs. 35-61. 
Bosque, I. (2001): «Sobre el concepto de ‘colocación’ y sus límites», Lingüistica Española Actual, 23:1, págs. 9-40.

Bosque, I. y V. Demonte (dirs.) (1999): Gramática descriptiva de la lengua española. Madrid, Espasa Calpe.

De Miguel, E. (1999): «El aspecto léxico». En Bosque, I. y V. Demonte (dirs.), págs. 2977-3060.

De Miguel, E. (2006): «Tensión y equilibrio semántico entre nombres y verbos: el reparto de la tarea de predicar». En Villayandre Llamazares, M. (ed.): Actas del XXXV Simposio Internacional de la Sociedad Española de Lingüística. León, Universidad de León, págs. 1289-1313: http://www3. unileon.es/dp/dfh/SEL/actas/Miguel.pdf (05-08-2008).

De Miguel, E. (2007): «El peso relativo de los nombres y los verbos: cambios, ampliaciones, reducciones y pérdidas del significado verbal». En Delgado, I. y A. Puigvert (eds.) Ex admiratione et amicitia. Homenaje a Ramón Santiago, Madrid: Ediciones del Orto, 295-326.

Dubský, J. (1984): «El valor explícito de las construcciones verbales y verbodenominales del español», Español Actual, 41, págs. 13-20.

Dubský, J. (1990a): «Al margen de la complementariedad léxico-sintáctica en español», Hispanica Posnaniensia, 1, págs. 31-37.

Dubský, J. (1990b): «El campo léxico de los verbos de introducción, de relación, de apoyo y verbos formemáticos». En Wotjak, G. y A. Veiga (coords.), La descripción del verbo español (Verba, Anexo 32). Santiago de Compostela, Universidade de Santiago de Compostela, págs. 107-111.

Dubský, J. (1998): «Debilitamiento del valor comunicativo del verbo español». En Wotjak, G. (ed.) (1998a), págs. 239-244.

González Ruiz, R. (2006): «Enunciados performativos y verbos performativos: Acerca de la performatividad como propiedad gradual (con especial referencia al español)», Hesperia. Anuario de Filología Hispánica, 9, págs. 107-126.

Gross, M. (1981): «Les bases empiriques de la notion de prédicat sémantique», Langages 63, págs. $7-52$.

Hausmann, F.-J. (1979): «Un dictionnaire des collocations est-il possible?», Travaux de littérature et de linguistique de l’Université de Strasbourg, 17:2, págs. 187-195.

Koike, K. (1993): «Caracterización y estructuras del verbo compuesto», Hispánica, 37, págs. 14-29.

Koike, K. (1998): «Algunas observaciones sobre colocaciones sustantivo-verbales». En Wotjak, G. (ed.) (1998a), págs. 244-255.

Koike, K. (2001): Colocaciones léxicas en el español actual. Estudio formal y léxico-semántico. Alcalá de Henares, Universidad de Alcalá/Takushoku Unviersity.

Lázaro Carreter, F. (dir.) (1980): Teoría y práctica de la lengua $6^{\circ}$. Madrid, Anaya.

Lyons, J. (1980): Semántica. Barcelona, Teide.

Martín Mingorance, L. (1998): «Las unidades sintagmáticas verbales en inglés y en español. Metodología de análisis». En Marín Rubiales, A. (ed.): El modelo lexemático-funcional. El legado lingüístico de Leocadio Martín Mingorance. Granada, Universidad de Granada, págs. 19-31.

Mel'čuk, I. (1992): «Paraphrase et lexique. La théorie Sens-Texte et le Dictionnaire explicatif et combinatoire». En Mel'čuk, I. et alii: Dictionnaire explicatif et combinatoire du français contemporain. Recherches lexicosémantiques III. Montreal, Les Presses de L’Université de Montréal, págs. 9-58.

Mel'čuk, I. (1995): «Phrasemes in Language and Phraseology in Linguistics». En Everaert, M., van der Linden, E.-J., Schenk, A. y R. Schreuder (eds.): Idioms. Structural and Psychological Perspectives. Hillsdale, Lawrence Erlbaum Associates, págs. 167-232.

Mel'čuk, I. (1997): Vers une linguistique Sens-Texte. Paris, Collègue de France.

Mel'čuk, I. (1998): «Collocations and Lexical Functions». En Cowie, A. P. (ed.), Phraseology. Theory, Analysis, and Applications. Oxford, Oxford University Press, págs. 23-53.

Mel'čuk, I. (2001): Communicative Organization in Natural Language. The Semantic-Communicative Structure of Sentences. Amsterdam/Philadelphia, Benjamins. 
Mel'čuk, I. y A. Žolkovskij (1970): «Towards a Functioning 'Meaning-Text' Model of Language», Linguistics, 57, págs. 10-47.

Mel'čuk, I., Clas, A. y A. Polguère (1995): Introduction à la lexicologie explicative et combinatoire. Louvain-la-Neuve, Duculot.

Mendívil Giró, J. L. (1999): Las palabras disgregadas. Sintaxis de las expresiones idiomáticas y los predicados complejos. Zaragoza, Prensas Universitarias de Zaragoza.

Mighetto, D. (1992): «Notas sobre la noción de aspecto en un marco de clasificación de verbos (Vb) y sustantivos verbales (Sv)», Voz y Letra, 3:1, págs. 69-100.

Piera, C. y S. Valera (1999): «Relaciones entre morfología y sintaxis». En Bosque, I. y V. Demonte (dirs.), págs. 4367-4422.

Polguère, A. e I. Mel'čuk (2006): «Dérivations sémantiques et collocations dans le DiCo/LAF», Langue Française, 150, págs. 66-83.

RAE: Banco de datos (CREA) [en línea]. Corpus de referencia del español actual: http://www.rae.es $(23 / 06 / 2008)$

Sanromán Vilas, B. (2003): Semántica, sintaxis y combinatoria léxica de los nombres de emoción en español. Helsinki: Yliopistopaino: https:/oa.doria.fi/bitstream/handle/10024/948/semantic. pdf? sequence=1 (19-06-2008).

Tornel Sala, J. L. (2000): Gramaticalización y vectores lingüisticos. Las perifrasis verbo-nominales. Alicante, Editorial Club Universitario.

Wanner, L. (ed.) (1996): Lexical Functions in Lexicography and Natural Language Processing. Amsterdam/ Philadelphia, John Benjamins.

Wotjak, G. (ed.) (1998a): Estudios de fraseología y fraseografía del español actual. Frankfurt am Main/ Madrid, Vervuert Verlag/Iberoamericana.

Wotjak, G. (1998b): «Reflexiones acerca de construcciones verbo-nominales funcionales». En Wotjak, G. (ed.) (1998a), págs. 257-279.

\section{Diccionarios y corpus}

CREA: RAE: Banco de datos [en línea]. Corpus de referencia del español actual: http://www.rae.es (26/06/2008).

DEA: Seco, M., Andrés, O. y G. Ramos (1999): Diccionario del español actual. Madrid, Aguilar.

DEC: Mel'čuk, I. et al. (1984-1999): Dictionnaire explicatif et combinatoire du français contemporain. Recherches lexico-sémantiques I-IV. Montréal, Les Presses de L’Université de Montréal.

DELE: Alvar Ezquerra, M. (dir.) (2006): Diccionario para la enseñanza de la lengua española. Español para extranjeros. Universidad de Alcalá/Barcelona, Vox_Bibliograf.

DiCoInfo: L'Homme, M.-C. (2008): Dictionnaire fondamental de l'information et de l'Internet: http:// olst.ling.umontreal.ca/ressources/base-dicoinfo/lang-pref/en/ (19-06-2008).

DRAE: RAE (2001): Diccionario de la lengua española. (22ª ed.). Madrid, Espasa Calpe. Se consultó también la versión en Internet: http://www.rae.es/rae.html (16-06-2008).

DSLE: Gutiérrez Cuadrado, J. (dir.) (2006): Diccionario Salamanca de la lengua española. Madrid, Santillana.

DUE: Moliner, M. (2007): Diccionario de uso del español (3 ed.). Madrid, Gredos.

FDS: Davies, M. (2006): A Frequency Dictionary of Spanish. Core Vocabulary for Learners. New York/ London, Routledge.

LAF: Mel'čuk, I. y A. Polguère (2007): Lexique actif du français. L'apprentissage du vocabulaire fondé sur 20000 dérivations sémantiques et collocations du français. Louvain-la-Neuve, De Boeck.

REDES: Bosque, I. (dir.) (2004): REDES. Diccionario combinatorio del español contemporáneo. Madrid, SM. 